\title{
Peertechz
}

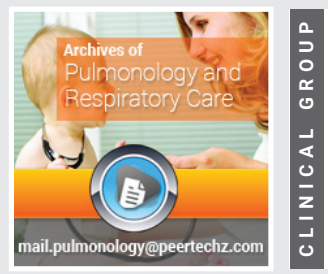

\section{Chronic obstructive pulmonary disease in patients with stable heart failure: Prevalence and associated factors}

Received: 27 December, 2019

Accepted: 21 December, 2020

Published: 22 December, 2020

*Corresponding author: Mbatchou Ngahane Bertrand Hugo, Faculty of Medicine and Pharmaceutical Sciences, University of Douala, Douala, Cameroon, Tel: +237 697068899; E-mail:mbatchou.ngahane@yahoo.com

Keywords: COPD; Epidemiology; Heart failure; Africa, Lung function

https://www. peertechz.com

Check for updates

\section{Mbatchou Ngahane Bertrand Hugo ${ }^{1,2 \star}$, Che Vanessa \\ Lum ${ }^{1}$, Abinkeng Tazifua Ebenezer ${ }^{1}$, Dzudie Anastase ${ }^{2}$, Ngote Roger ${ }^{2}$, Kamdem Felicité ${ }^{1,2}$ and Mandengue Samuel Honoré ${ }^{3}$}

${ }^{1}$ Faculty of Medicine and Pharmaceutical Sciences, University of Douala, Douala, Cameroon

${ }^{2}$ Department of Internal Medicine, Douala General Hospital, Douala, Cameroon

${ }^{3}$ Faculty of Sciences, University of Douala, Douala, Cameroon

\begin{abstract}
Background: Chronic Obstructive Pulmonary Disease (COPD) is characterized by irreversible airflow limitation in the lungs. COPD frequently coexist with Heart Failure (HF) but most patients go undiagnosed because of similarity of symptoms. Data on prevalence of COPD in HF are discrepant and scarce. In addition, associated factors of COPD in these patients have not been completely investigated. Our objectives were to determine the prevalence of COPD amongst stable HF patients and to identify the factors associated.
\end{abstract}

Methods: It was a cross-sectional study carried out from January 2016 to April 2016 at the Douala General Hospital. All stable HF patients 40 years and over who came for routine follow-up and who met up inclusion criteria were enrolled. A questionnaire was used to obtain information on pulmonary symptoms, risk factors, sociodemographic data, comorbidities and spirometric measurements. COPD was defined by airflow limitation which corresponds to the ratio of post-broncho dilation forced expiratory volume in one second on the forced vital capacity less than 70\% (FEV1/FVC $<70 \%$ ). SPSS 20 software was used for data analysis and a P-value $<0.05$ was considered significant.

Results: A total of $86 \mathrm{HF}$ patients were included in our study. The median age was 66.5 years with an Interquartile Range (IQR) of 57-75years. Female sex was the most represented (53.3\%). Twenty-two patients had COPD giving a prevalence of COPD in HF of $25.6 \%$ (95\%Cl; 16-34). Sputum production was significant in those with $\operatorname{COPD}(p=0.012)$ and elderly age $(\geq 65$ years $)$ was associated with COPD $(p=0.026)$.

Conclusion: Our findings suggest that one out of four patients diagnosed with heart failure has chronic obstructive pulmonary disease with sputum production being the most likely symptom and elderly age an associated factor of having COPD in heart failure. Clinicians should think of an associated COPD when investigating patients with heart failure.

\section{Abbreviations}

COPD: Chronic Obstructive Pulmonary Disease; HF: Heart Failure; FEV1: Forced Expiratory Volume in one Second; FVC: Forced Vital Capacity; SPSS: Statistical Package Social Software; IQR: Interquartile Range; CI: Confidence Interval; ERS: Euro- pean Respiratory Society; ATS: American Thoracic Society; IRB: Institutional Review Board; BMI: Body Mass Index; GOLD: Global Initiative for Obstructive Lung Disease

\section{Introduction}

Global initiative for Chronic Obstructive Pulmonary 
Disease defines COPD as "A common preventable and treatable disease, characterized by persistent airflow limitation that is usually progressive and associated with an enhanced chronic inflammatory response in the airways and the lung to noxious particles or gases [1]. Chronic Obstructive Pulmonary Disease represents a major public health problem, and its mortality is expected to rise in future [2]. The prevalence of COPD in the world's population is considered to be around $1 \%$ concerning all age groups, rising to $8-10 \%$ or more in individuals $>40$ years old [3]. In Europe, the prevalence of Spirometry-defined COPD is about $10 \%$ [4]. A systematic review based on Spirometrydefined prevalence revealed that 227.3million was diagnosed with COPD in 1990 amongst people aged 30years or more which increased to 384 million by 2010 . In $2010,28.5$ million cases of COPD were identified in Africa [5]. A study carried out by Buist, et al. in Cape Town, South Africa in 2007 revealed that the estimated prevalence was $22.2 \%$ in males and $16.7 \%$ in females [6]. Smoking is the main risk factor of COPD. Indoor air pollution and occupational exposure also cause COPD [7]. Smoking is common in Cameroon and the use of firewood for cooking is a common activity especially among women.

Heart failure happens when the heart cannot pump enough blood and oxygen to support organs in the body [8]. Heart failure (HF) is a major health concern affecting over 5.8 million person in united states and 23 million in the world $[8,9]$. A diagnosis of HF carries substantial risk of morbidity and mortality, despite advances in management [10,11]. Over 2.4 million patients who are hospitalized have $\mathrm{HF}$ as a primary or secondary diagnosis, and nearly 300,000 deaths annually are directly attributable to HF. Most of the HF burden is borne by individuals aged greater than or equal to ( $\geq) 65$ years, who account for more than $80 \%$ of the deaths and prevalent cases in the USA and Europe [9]. Heart failure is the first cause of hospital admission among patients with high blood pressure in Africa. In internal medicine services, heart failure has been described as the fifth to sixth cause of hospital admissions $[10,11]$. The prevalence of heart failure in Cameroon is $30 \%$ [12].

HF and COPD commonly coexist and are important differential diagnosis to each other due to the fact that they share similar clinical presentation such as dyspnea, fatigue, and cough and common risk factors such as smoking and age [13]. Diagnosing COPD in HF is challenging because clinical features overlap. Under diagnosis of one disease in the presence of the other is an important issue [14]. There is also risk of over diagnosing COPD in HF if these patients are not stable and have some pulmonary congestion because it mimics COPD clinically and spirometrically so when patients are stable spirometry allows for adequate detection of COPD [13]. Coexistence of COPD and HF in patients gives them worse stable health state compared to patients with just one of the two $[13,14]$. This leads to an increasing challenge in their management $[15,16]$. Studies have shown the prevalence of COPD in patients with stable $\mathrm{HF}$ in developed countries to range from 10 to $33 \%$ $[15,17]$. A systemic review done in 2009 showed the following prevalences of COPD in hospitalized heart failure patients; Malaysia $12 \%$, USA $24 \%$, Canada $21 \%$, Netherlands $19 \%$, with an overall prevalence ranging from $9 \%$ to 52 [18]
Due to the fact that COPD is an important disease with its increasing prevalence and morbidity and the fact that most $\mathrm{HF}$ patients go undiagnosed because of similar symptoms; and with the scarcity of studies on their co-existence, knowing the prevalence of COPD in HF out patients in Cameroon will create awareness of this coexistence to practitioners so that management of the patients may be intensified. This will also serve as baseline study for future studies on $\mathrm{COPD} / \mathrm{HF}$ comorbidity.

\section{Materials and methods}

\section{Study design}

It was across-sectional descriptive study conducted from January to April 2016.

\section{Site of study}

This study was carried out at the Douala General Hospital which is a specialized health care structure at the central level of Cameroon health system located at the North-East of Douala. The study was carried out in the following units, the Pneumology unit and the cardiology outpatient consultation unit. The Pneumology unit headed by a Pneumologist and has exploration units amongst which spirometry is part. The cardiology unit constitutes 5 cardiologists and divided into the outpatient, exploration and hospitalization units. The cardiologists work on a daily basis receiving patients from the city and its environ.

\section{Study population}

We consecutively included outpatients attending cardiologic outpatients unit. The participants consisted of patients who are diagnosed of heart failure and followed up by a cardiologist at the Douala General hospital. Were included all cardiology outpatients aged 40 years and above, diagnosed with heart failure and who were stable. We excluded patients who had not given their consent, patients with contraindication for spirometry according to ERS-ATS guidelines, known asthmatic patients and patients on B-blockers medication.

\section{Data collection}

We started by doing a pilot-test to ensure that the methodology is adapted. During specialized consultations, an invitation was offered to patients diagnosed with heart failure through the explanation of the purpose and procedure of the study. Patients who gave their consent were recruited. In a one-to-one interview, a questionnaire was used to obtain information from patients as regards socio-demographic data, respiratory symptoms, cigarette smoking and biomass exposure, occupational exposure, co-morbidities, medication. This was followed by spirometry measurement. ethical clearance was gotten from the Institutional Review Board (IRB) of the Faculty of Medicine and Pharmaceutical Sciences of the University of Douala while administrative clearance was obtained from the hospital authorities before we started the recruitment. 


\section{Spirometry measurement}

This was done using a spirometer marked EasyOne ${ }^{\mathrm{TM}}$ (ndd Medizintechnik AG, Zurich, Switzerland) and according to American Thoracic Society/European Respiratory Society guidelines for subject maneuver, techniques, and quality control [19]. The procedure was explained and demonstrated to the participant to ensure he/she will be able to perform the procedure well. At the end of the procedure, the spirometer was connected to a computer and the results were uploaded and printed. COPD was defined as a post-bronchodilation. FEV1/ FVC $<70 \%$ with FVC $>80 \%$. The best values of the acceptable and reproducible curved were selected and interpreted.

\section{Quality control}

Interviews and spirometry were conducted by the investigator. Strict quality control program was used to standardize spirometry and the spirometer was calibrated weekly. The results were interpreted by the Pneumologist and data was reviewed, cleaned and analyzed.

\section{Variables}

The following data were collected using a data collection sheet.

\section{Sociodemographic data: Age, sex, profession.}

Anthropometric parameters: Weight, height, BMI (calculated from the formula weight/height ${ }^{2}$, weight collected with the help of a scale balance and height from a stadiometer - patient standing at the anatomical position in front of the stadiometer.

Clinical data: Respiratory symptoms (cough, dyspnea, sputum production, wheezing), comorbidities (hypertension, diabetes, tuberculosis, stroke, gastro esophageal reflux, cardiovascular drugs.

Risk factors: Smoking, biomass fuel exposure, occupational exposure.

Spirometric data: Pre-bronchodilation and postbronchodilation values of Forced expiratory volume at 1 second (FEV1), Forced vital capacity (FVC), Ratio of forced expiratory volume at 1 second and forced vital capacity (FEV1/FVC), Percentage predicted value of FEV1.

\section{Definition of terms and concepts}

COPD/HF co-morbidity: coexistence of chronic obstructive pulmonary disease and heart failure (i.e. a patient has at the same time COPD and heart failure).

Smoking: Current smoker is an individual who has smoked cigarettes regularly for at least one year. Ex-smoker is an individual who has smoked regularly but had quit smoking for at least six months. Non-smoker is an individual who has never smoked. Passive smoker is one who has never smoked but had a history of daily cigarette smoke inhalation of more than three hours per day.

Stable heart failure: Patients diagnosed with HF who are not decompensating, that is not presenting with signs and symptoms of heart failure.

Biomass fuel exposure: Exposure to smoke from burning firewood and charcoal.

Occupational exposure: Exposure to dust in workplace.

Airflow limitation: Post bronchodilator FEV1/FVC $<0.70$ $(70 \%)$.

Spirometric definition of COPD: Airflow limitation Post bronchodilator FEV1/FVC $<0.70$, with no significant reversibility that is FEV1 change $<200 \mathrm{ml}(<12 \%)$.

\section{Data analysis}

Data was entered, cleaned and analyzed using the software Statistical Package Social Software (SPSS) version 20 of Windows. Descriptive statistics included medians and interquartile range. Categorical variables were summarized using frequencies and percentages. Continues and categorical data were compared using Man Whitney and Chi-square test or the Fischer test. Statistical significance level was fixed at $\mathrm{p}$ value $<0.05$

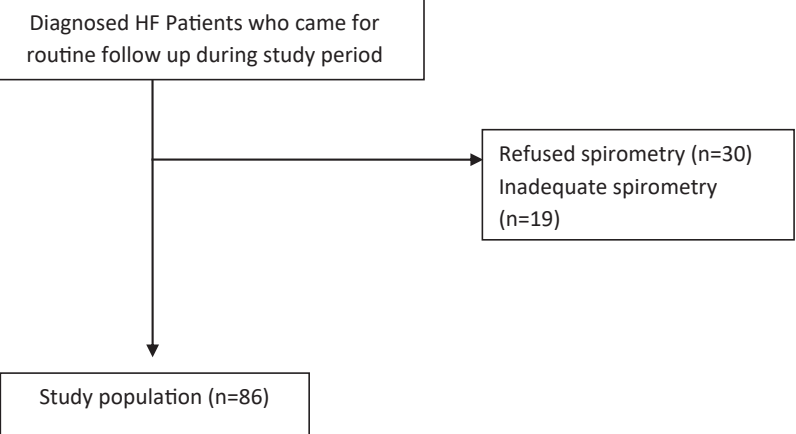

Figure 1: Flow chart for the presentation of recruitment

\section{Results}

The Figure 1 below shows how we arrived at our study population of 86 participants;

\section{General characteristics of the study population}

The study population was made up of $45(52.3 \%)$ women. The most frequently reported symptoms were dyspnoea (98.8\%) followed by cough (37.8\%). Most patients (95\%) referred to dyspnoea in grade 2 of New York Hearth Association. The most frequent comorbidity was hypertension while the main risk factor of COPD was exposure to biomass smoke. The other characteristics are shown in Table 1.

Of the 86 participants, 22 had a post-broncho dilation FEV1/ $\mathrm{FVC}<70 \%$ giving a prevalence of COPD in stable $\mathrm{HF}$ of $25.6 \%$ ( $95 \%$ CI; 16 - 34). The majority of COPD patients $(77.3 \%)$ were at the second stage of COPD according to GOLD classification while $18.20 \%$ and $4.50 \%$ were respectively at stage 3 and 4 . 
Sputum production was the significant symptom of COPD. Post-bronchodilation FEV1 was significantly lower in COPD patients $(1.26 \mathrm{ml})$ than among patients without COPD $(1.83 \mathrm{ml})$ (Table 2).

Elderly age was significantly associated in COPD (Table 3). Smoking and biomass fuel exposure as well as occupational exposure were not associated with COPD. The median age of participants with COPD was 75 years while it was 64 years in those without COPD.

\section{Discussion}

The aim of this our study was to determine the prevalence

Table 1: Baseline characteristics of the participants.

\begin{tabular}{|c|c|}
\hline Characteristics & Heart failure patients \\
$\mathbf{( N = 8 6 )}$
\end{tabular}

Table 2: COPD symptoms and spirometric parameters in patients with and without COPD.

\begin{tabular}{|c|c|c|c|}
\hline & COPD $(\mathbf{n}=\mathbf{2 2})$ & No COPD $(\mathbf{n}=\mathbf{6 4})$ & p-value \\
\hline $\begin{array}{c}\text { Chronic cough } \\
\text { Yes } \\
\text { No }\end{array}$ & $12(54.5 \%)$ & $20(31.3 \%)$ & \\
\hline $\begin{array}{c}\text { Sputum production } \\
\text { Yes } \\
\text { No }\end{array}$ & $10(45.5 \%)$ & $44(68.7 \%)$ & 0.510 \\
\hline $\begin{array}{c}\text { Wheezing } \\
\text { Yes }\end{array}$ & $5(22.7 \%)$ & $3(4.7 \%)$ & 0.012 \\
No & $17(76.3 \%)$ & $61(95.3 \%)$ & \\
\hline Breathlessness & $1(4.5 \%)$ & $1(1.6 \%)$ & 0.423 \\
Yes & $21(95.5 \%)$ & $63(98.4 \%)$ & \\
No & $22(100 \%)$ & $63(98.4)$ & 0.555 \\
\hline FEV1 (median (IQR) & $1.26(1.02-1.61)$ & $1.83(1.50-2.27)$ & 0.000 \\
\hline FVC (median) & $2.03(1.62-2.99)$ & $2.26(1.86-2.81)$ & 0.263 \\
\hline
\end{tabular}

Table 3: Factors associated with COPD.

\begin{tabular}{|c|c|c|c|}
\hline & COPD $(n=22)$ & No COPD $(n=64)$ & p-value \\
\hline $\begin{array}{l}\text { Gender } \\
\text { Male } \\
\text { Female }\end{array}$ & $\begin{array}{l}11(50 \%) \\
11(50 \%)\end{array}$ & $\begin{array}{l}29(45.3 \%) \\
35(54.7 \%)\end{array}$ & 0.70 \\
\hline $\begin{array}{l}\text { Age (years) } \\
\quad>65 \\
\leq 65\end{array}$ & $\begin{array}{c}16(72.7 \%) \\
6(27.3 \%)\end{array}$ & $\begin{array}{l}29(45.3 \%) \\
35(54.7 \%)\end{array}$ & 0.026 \\
\hline $\begin{array}{l}\text { Smoking } \\
\text { Former } \\
\text { Never }\end{array}$ & $\begin{array}{c}7(31.8 \%) \\
15(68.2 \%)\end{array}$ & $\begin{array}{l}13(20.3 \%) \\
51(79.7 \%)\end{array}$ & 0.27 \\
\hline $\begin{array}{c}\text { Biomass fuel exposure } \\
\text { Yes } \\
\text { No }\end{array}$ & $\begin{array}{l}10(45.5) \\
12(54.5)\end{array}$ & $\begin{array}{c}28(43.7 \%) \\
36(56.3)\end{array}$ & 0.604 \\
\hline $\begin{array}{l}\text { Occupational exposure } \\
\qquad \begin{array}{c}\text { Yes } \\
\text { No }\end{array}\end{array}$ & $\begin{array}{c}1(4.5 \%) \\
21(95.5)\end{array}$ & $\begin{array}{l}3(4.7 \%) \\
61(95.3)\end{array}$ & 0.78 \\
\hline $\begin{array}{l}\text { BMI } \\
<18.5 \\
\geq 30\end{array}$ & $\begin{array}{l}1(4.5 \%) \\
1(4.5 \%)\end{array}$ & $\begin{array}{c}5(7.8 \%) \\
10(15.6 \%)\end{array}$ & $\begin{array}{l}0.55 \\
0.71\end{array}$ \\
\hline
\end{tabular}

of chronic obstructive pulmonary disease in stable heart failure patients and to determine the factors associated of COPD. From our results, we found a prevalence of $25.6 \%$. Sputum production was the significant symptom in heart failure patients with COPD. Elderly age was the associated factor to have COPD in heart failure.

In our study, amongst stable heart failure patients, 22 of the 86 participants had post-bronchodilation FEV1/FVC less than $70 \%$ with no significant reversibility that is FEV1 change less than $200 \mathrm{ml}$. This gave a prevalence of COPD amongst stable heart failure patients of $25.6 \%$. This is similar to a cross-sectional study carried out by Valk, et al. . on 106 stable heart failure patients with a prevalence of $28.3 \%$. In their study, COPD was also defined using GOLD criteria [13]. Our study is also in line with a review study by Iversen, et al. with prevalence ranging from $10 \%$ to $33 \%$ [15]. Also, a review of studies done on hospitalized unstable heart failure patients by Hawkins, et al. found a prevalence ranging from 9 to $52 \%$ [18]. Most of our patients diagnosed with COPD were classified as moderate (stage II) COPD. This coincides with the findings of Gulmisal, et al. where most of the participants were classified as having mild to moderate COPD [20]. Contrarily, in the study carried out by Mascarenas, et al. most of the patients were classified as severe and very severe (stage III and IV) [21]. Median FEV1 percentage predicted in heart failure patients in our study was $91.7 \%$ this does not coincide with the fact that heart failure without COPD may cause a 20 reduction in FEV1 as seen in other studies like study by Valk, et al. the mean FEV1 in patients with just heart failure was $80 \%$. We found in our study that sputum production was a significant symptom in heart failure patients with COPD. However, cough, dyspnea and wheezing were insignificant. This is not far from the findings of Minasian, et al. who found that sputum production, cough and dyspnea were determinants of COPD. In their study, Patients who had COPD and heart failure presented more with above symptoms than those with just heart failure [17]. Other studies revealed that these symptoms overlap in both comorbidities

Citation: Bertrand Hugo MN, Lum CV, Ebenezer AT, Anastase D, Roger N, et al. (2020) Chronic obstructive pulmonary disease in patients with stable heart failure: Prevalence and associated factors. Arch Pulmonol Respir Care 6(1): 090-095. DOI: https://dx.doi.org/10.17352/aprc.000065 
like the study by Iversen, et al. [15]. This implies a stable heart failure patient presenting with cough and sputum production had a high probability of having COPD.

In this study, we found that elderly age (65 years and above) was significantly associated with COPD. This agrees with results of Apostolovic, et al. where age greater than 65 years was an associated factor of COPD [16]. We found a median age of 70 years amongst our patients with COPD which was greater than the median age of those without COPD (64 years). Valk J, et al. had similar findings, with mean age of 76.9 years amongst COPD and 75.8 years in patients with no COPD [13]. This supports the fact that ageing is a factor associated with COPD [16]. Smoking was not significantly associated to COPD, contrary to the study by Minasian, et al. who found that smoking was a determinant of COPD in heart failure [17]. This can be due to the fact that smoking is more common in their context. Other studies consider smoking as the main risk factor of the two comorbidities like that by Berkhof, et al. [14]. Exposure to biomass combustion is a known risk factor of COPD especially in our context. However, it was not significant in our study. A probable explanation to this is that participants might have underappreciated their exposure to biomass combustion. Household air pollution from solid fuel use in kitchens did not sound as a problem to users during data collection. Occupational exposure was not significant. Most of the patients had normal body mass index. BMI less than 18.5 was insignificant. The percentage of male sex affected was $50 \%$ which is not in line with the previous studies by Valk, et al. [13], Apostolovic, et al. [16] where males were more proportionately affected. This can be due to the fact that women were more exposed to biomass combustion than men in our study and also probably because female sex was predominant.

\section{Limitations of our study}

Our sample size was small because of the difficulty of spirometry measurement and short study period. Furthermore, improper filling of files prevented us from comparing those with reduced ejection fraction to those with preserved ejection fraction and to assess the etiologies of heart failure.

\section{Conclusion}

One in four stable heart failure patients has COPD. There is co-existence between COPD and HF and many patients go undiagnosed because of the overlapping of presenting symptoms. Patients with the COPD/HF co-morbidity present more with chronic sputum production than those with just heart failure. Elderly age is an associated factor for developing COPD. Lung function should be tested in patients with heart failure especially in elderly and when there is cough with sputum production.

\section{Acknowledgments and disclaimer}

We thank the NIHR Global Health Research Unit on Lung Health and TB in Africa at LSTM - "IMPALA" for helping to make this work possible. In relation to IMPALA (grant number 16/136/35) specifically: This research was funded by the
National Institute for Health Research (NIHR) (IMPALA, grant reference 16/136/35) using UK aid from the UK Government to support global health research. The views expressed in this publication are those of the author(s) and not necessarily those of the NIHR or the UK Department of Health and Social Care."

\section{References}

1. Pauwels R.A, Buist A.S, Calverley PM (2001) Global Strategy for the diagnosis, management and prevention of Chronic Obstructive Pulmonary disease. NHLBIWHO Glob. Initiat. Chronic. Obstr. Lung. Dis. GOLD Workshop Summary 163: 1256-1276. Link: http://bit.ly/2KrQ7wd

2. Lopez A, Shibuya K, Rao C, Mathers C, Hansell A, Held L (2006) Chronic Obstructive Pulmonary Disease: current burden and future projections. Eur Respir J 27: 397-412. Link: http://bit.ly/3h832zt

3. Halbert RJ, Natoli JL, Gano A, Badamgarav E, Buist AS, et al. (2006) Global burden of COPD.Systematic review and meta-analysis. Eur Respir J 28: 523532. Link: http://bit.ly/3h8Ddiw

4. Buist AS, McBurnie MA, Vollmer WM, Gillespie S, Burney P (2007) International variation in the prevalence of COPD (the BOLD Study): a population-based prevalence study. Lancet 370: 741-750. Link: http://bit.ly/3rfGbGP

5. Adeboye D, Chua S, Lee C, Basquill C, Papana A, et al. (2015) Global and Regional estimates of COPD prevalence: Systematic review and metaanalysis. J Glob Health 5: 020415. Link: http://bit.ly/3aue1ln

6. Mehrotra A, Oluwole M, Gordon B (2009) The burden of COPD in Afric: a literature review and prospective survey of the availability of spirometry for COPD diagnosis in Africa. Trop Med Int Health 14: 840-848. Link: http://bit.ly/3pd4rYo

7. Naidoo R, Robins T, Murray J (2005) Respiratory outcomes among South African coal Miners in Autopsy. Am J Ind Med 43: 217-224. Link: http://bit.ly/38miCnc

8. Bui AL, Horwich TB, Fonarow GC (2011) Epidemiology and risk profile of heart failure. Nat Rev Cardiol 8: 30-41. Link: http://bit.ly/3alZiZL

9. McMurray JJV, Stewart S (2002) The burden of heart failure. Eur Heart J 4 50-58. Link: https://bit.ly/3nCqszv

10. Tantchou T, Cabral A, Kingue S, Giamberti A, Cirri S, et al. (20110ccurrence, aetiology and challenges in the management of congestive heart failure in sub-saharan Africa: experience of the Cardiac Centre in Shisong, Cameroon. Pan Afr Med J 8: 11. Link: http://bit.ly/2Kg06VD

11. Tantchou T, Butera G (2013) Profile of cardiac disease in Cameroon and impact on health care services. Cardiovascular Diagnosis and Therapy 3: 236243. Link: http://bit.ly/2Wxj0d5

12. Kengne P, Dzudie A, Sobngwi E (2008) Heart failure in sub-Saharan Africa: A literature review with emphasis on individuals with diabetes. Vasc Health Risk Manag 4: 123-130. Link: http://bit.ly/2WBtAQ2

13. Valk J, Broekhuizen B, Mosterd A, Zuithoff N, Hoes A, et al. (2015) COPD in patients with stable heart failure in the primary care setting. Int $\mathrm{J}$ Chron Obstruct Pulmon Dis 10: 1219-1224. Link: http://bit.ly/3arpnqp

14. Berkhof F, Metzemaekers L, Uil S, Kerstjens H, Van den Berg J (2014) Health status in patients with coexistent COPD and heart failure: a validation and comparison between the Clinical COPD Questionnaire and the Minnesota Living with Heart Failure Questionnaire. Int J Chron Obstruct Pulmon Dis 9: 999-1008. Link: http://bit.ly/3h5UjxG

15. Iversen K, Kjaergaard J, Akkan D, Kober L, Torp-Pedersen C, et al. (2008) Chronic obstructive pulmonary disease in patients admitted with heart failure. J Intern Med 264: 361-369. Link: http://bit.ly/38orMPV 
16. Apostolovic S, Jankovic R, Salinger S, Djordjevic D, Stanojevic D, et al. (2011) Frequency and significance of unrecognized chronic obstructive pulmonary disease in elderly patients with stable heart failure. Aging Clin Exp Res 23: 337 342. Link: http://bit.ly/3mx6p40

17. Minasian A, Dekhuijzen R, Vos J, Willems F, Van den Bergh P, et al. (2013) COPD in chronic heart failure: Less common than previously thought. Heart Lung Circ 365-371. Link: http://bit.ly/3h8uAF2

18. Hawkins N, Petrie C, Jhund P, Chalmers G, Dunn F, et al. (2009) Heart failure and chronic obstructive pulmonary disease: diagnostic pitfalls and epidemiology. Eur J Heart Fail 11: 130-139. Link: http://bit.ly/3mCRIfJ
19. Miller MR, Hankinson J, Brusasco V, Burgos F, Casaburi R, et al. (2005) ATS/ ERS Task Force. Standardisation of spirometry. Eur Respir J 26: 319-338. Link: http://bit.ly/3h63gqC

20. Gülmisal G, Susanne B, Stefan S, Arno H, Frans H (2014) Chronic obstructive pulmonary disease in heart failure: accurate diagnosis and treatment. Eur $J$ Heart Fail 16: 1273-1282. Link: http://bit.ly/34ybnqZ

21. Mascarenhas J, Lourenço P, Lopes R, Azevedo A, Bettencourt P (2008) Chronic obstructive pulmonary disease in heart failure. Prevalence, therapeutic and prognostic implications. Am Heart J 155: 521-525. Link: http://bit.ly/3rqN1cK

\section{Discover a bigger Impact and Visibility of your article publication with}

\section{Peertechz Publications}

\section{Highlights}

- Signatory publisher of ORCID

* Signatory Publisher of DORA (San Francisco Declaration on Research Assessment)

* Articles archived in worlds' renowned service providers such as Portico, CNKI, AGRIS, TDNet, Base (Bielefeld University Library), CrossRef, Scilit, J-Gate etc.

* Journals indexed in ICMJE, SHERPA/ROMEO, Google Scholar etc.

* OAI-PMH (Open Archives Initiative Protocol for Metadata Harvesting)

* Dedicated Editorial Board for every journal

* Accurate and rapid peer-review process

* Increased citations of published articles through promotions

* Reduced timeline for article publication

Submit your articles and experience a new surge in publication services (https://www.peertechz.com/submission).

Peertechz journals wishes everlasting success in your every endeavours

Copyright: ( 2020 Bertrand Hugo MN, et al. This is an open-access article distributed under the terms of the Creative Commons Attribution License, which permits unrestricted use, distribution, and reproduction in any medium, provided the original author and source are credited.

Citation: Bertrand Hugo MN, Lum CV, Ebenezer AT, Anastase D, Roger N, et al. (2020) Chronic obstructive pulmonary disease in patients with stable heart failure: Prevalence and associated factors. Arch Pulmonol Respir Care 6(1): 090-095. DOI: https://dx.doi.org/10.17352/aprc.000065 